\title{
Inquiries respecting the dimensions and value of the local measures in common use at Covent Garden market
}

\section{B. Bevan Esq.}

To cite this article: B. Bevan Esq. (1832) Inquiries respecting the dimensions and value of the local measures in common use at Covent Garden market, Philosophical Magazine Series 3, 1:6, 472-472, DOI: $10.1080 / 14786443208647948$

To link to this article: http://dx.doi.org/10.1080/14786443208647948

曲 Published online: 01 Jun 2009.

Submit your article to this journal $[\pi$

Џll Article views: 2

Q View related articles $\llbracket$ 
tached rocks, and which rest upon the bed, and are also under it in many places. It seems, in fact, that these substances have fallen upon the bed, and covered it over after its formation by the sea; and in time the mass has become so consolidated, as often to present nearly a perpendicular surface to the sea, of from thirty to fifty or sixty feet in height.

In some parts of the cliff, particularly within the parishes of Budock and Mawnan, the pebbles and gravel have been formed into a conglomerate, apparently, by the oxides of iron and manganese. The bed may have been produced by a succession of extraordinarily high tides, resulting from some long operating or more temporary cause, at a very remote period. However this may have been, the fact is curious, and seems to be at variance with the notion, that the sea has made considerable encroachments on the coasts of Cornwall.

If it should be surmised that the land itself might have been elevated, it may be remarked, that such an hypothesis is not in accordance with the horizontal position of the bed for so considerable a distance, notwithstanding that the cliffs are in many places intersected by valleys.

INQUIRIES RESPECIING THE DIMENSIONS AND VALUE OF THE LOCAL MEASURES IN COMMON USE A'T COVENT GARDEN

MARKET. BY B. BEVAN, ESQ.

To the Editors of the Phil. Mag. and Journal of Science.

Sometime last year, I inquired through the medium of the Gardener's Magazine, (as the most probable channel for the information sought,) the dimensions of the local measures in common use at $\mathrm{Co}_{0}$ vent Garden market; at present no one has thought proper to favour the public, through that channel, with a specification of those measures, which are generally unknown to country gardeners, and on that account the relative prices of fruit and vegetables in the country are also unknown.

The Sieve, being a measure frequently used, its diameter and depth should be specified.

The Half-sieve also,-for although it is so denominated, it may not perhaps usually contain half the quantity of a sieve.

The Punnet should also be defined, by specifying its dimensions, or by naming its proportion to some known measures.

The Pottle, is a measure already known; but probably there may be some variation in the local pottle of Covent Garden and the Imperial pottle.

There are some other articles sold by the Bunch, which to a countryman is an undefined quantity. If any person would take the trouble to ascertain the weight of these bunches, and favour the public, through the medium of your Magazine, with the information, it would be acceptable to many in the country.

The trouble of ascertaining the dimensions of the measures above described, will be very little.

The gallon and pottle measures, perhaps, may be not quite conformable to the general Act, in the proportion of their diameters to their dejths. Yours, \&c.

B. BEVAN. 